\title{
Ultra-high-strength Bainitic Steels
}

\author{
C. GARCIA-MATEO and F. G. CABALLERO
}

Department of Physical Metallurgy, Centro Nacional de Investigaciones Metalúrgicas (CENIM-CSIC), Avda. Gregorio del Amo, 8, 28040, Madrid, Spain. E-mail: cgm@cenim.csic.es

(Received on April 4, 2005; accepted on July 21, 2005)

\begin{abstract}
Novel bainitic microstructures, consisting of slender ferrite plates (tens of $\mathrm{nm}$ ) in a matrix of retained austenite, have reported maximum yield strength of $1.4 \mathrm{GPa}$, ultimate tensile strength of $2.2 \mathrm{GPa}, 30 \%$ ductility and respectable levels of fracture toughness ( $51 \mathrm{MPa}$ m0.5). The unusual combination of properties is attributed to the fine bainitic plates and the presence of retained austenite in the microstructure.
\end{abstract}

KEY WORDS: bainite; mechanical properties; plate thickness; dislocation density; carbon content.

\section{Introduction}

A new generation of bainitic steels has recently been developed using detailed phase transformation theory for the bainite reaction. The calculations are based on the model that nucleation occurs under paraequilibrium conditions and that the nucleus evolves into a plate by diffusionless growth. ${ }^{1)}$ The steels have a simple metallurgy which can be summarized as follows ${ }^{2-5)}$ :

- low bainitic and martensitic transformation temperatures ( $\mathrm{B}_{\mathrm{S}}$ and $\mathrm{M}_{\mathrm{S}}$ respectively) both to maximize the fraction of bainite and to reduce the scale of the microstructure,

- the precipitation of cementite is avoided by alloying with silicon,

- in spite of the low transformation temperatures, the steel is designed to achieve the required bainitic microstructure in realistic time-scales during isothermal transformation.

Furthermore, the hardenability is engineered so that phases such as allotriomorphic ferrite and pearlite are avoided during cooling from the austenitisation temperature.

In this work, a study of the existing correlation between mechanical properties and microstructure features for a selected variant of the new alloy system is presented.

\section{Materials and Experimental Procedure}

The chemical compositions of the alloys used are listed in Table 1. The alloys contain manganese and chromium for hardenability, and silicon to prevent cementite precipitation during bainitic transformation ${ }^{1)}$; thus, the carbon that is rejected into the residual austenite, instead of precipitating, remains in the austenite and stabilizes it down to ambient temperature. Molybdenum is added to prevent temper embrittlement due to phosphorous. ${ }^{6}$ ) The carbon concentration was selected to suppress $B_{S}$ whilst at the same time allowing realistic transformation times. Cobalt and aluminum are added to accelerate the rate of reaction by increasing the free energy difference between the ferrite and austenite phases. Detailed information on the metallurgical design of the alloys and of the heat treatment is given in. ${ }^{5)}$ Lumps of the materials where homogenized at $1200^{\circ} \mathrm{C}$ during $2 \mathrm{~d}$ followed by slow cooling rate to ambient temperature by switching off furnace to obtain pearlite as the microstructure. This is important in order to avoid martensite; because of the high carbon concentration, martensite plates tend to crack spontaneously, thereby compromising the integrity of the sample. The vacuum furnace was also used to protect subsequent samples against oxidation during austenitisation at $900^{\circ} \mathrm{C}$ for $30 \mathrm{~min}$ prior to isothermal heat treatments. Those were performed at 200,250 and $300^{\circ} \mathrm{C}$ during 96,16 and $6 \mathrm{~h}$ respectively.

X-ray experiments were conducted using a Phillips PPW1730 diffractometer and a scanning rate $(2 \theta)$ of $0.1^{\circ} \mathrm{min}^{-1}$ over the range $2 \theta=30-110^{\circ}$, with unfiltered $\mathrm{CuK}_{\alpha}$ radiation. The system was operated at $45 \mathrm{kV}$ and $45 \mathrm{~mA}$. The retained austenite volume fraction was calculated using integrated intensities of the $\{111\},\{200\}$, $\{220\}$ and $\{311\}$ austenite peaks and the $\{110\},\{002\}$, $\{112\}$ and $\{022\}$ peaks of ferrite. Using this number of peaks avoids possible bias due to crystallographic texture. ${ }^{7)}$ The ferrite carbon content was calculated making use of the relationship between lattice parameter and chemical composition as reported in Ref. 8) The X-ray data from the microstructure were also analyzed for non-uniform strains. Diffraction peaks are broadened by the presence of nonuniform strains that systematically shift atoms from their ideal positions, and by the finite size of coherently diffracting domains. These two effects have a different dependence on the value of $\theta$, which is the Bragg angle. ${ }^{9)}$ The non-uniform strain effect can therefore be separated, since the slope of a plot of $\beta_{h k l} \cos \left\{\left(\theta_{h k l}\right\}\right.$ versus $4 \sin \left\{\left(\theta_{h k l}\right\}\right.$ is equal to a

Table 1. Chemical composition in $\mathrm{wt}^{\mathrm{\%}} \%$.

\begin{tabular}{|l|ccccccccc|}
\cline { 2 - 10 } \multicolumn{1}{c|}{} & $\mathrm{C}$ & $\mathrm{Si}$ & $\mathrm{Mn}$ & $\mathrm{Mo}$ & $\mathrm{Cr}$ & $\mathrm{Co}$ & $\mathrm{Al}$ & $\mathrm{P}$ & $\mathrm{S}$ \\
\hline Alloy 1 & 0.80 & 1.59 & 2.01 & 0.24 & 1 & 1.51 & & 0.002 & 0.002 \\
Alloy 2 & 0.79 & 1.56 & 1.98 & 0.24 & 1.01 & 1.51 & 1.01 & 0.002 & 0.002 \\
\hline
\end{tabular}


measure of the non-uniform strain $\varepsilon{ }^{9)}$ The parameter $\beta$ is the measured peak broadening. The dislocation density, $\rho$, is calculated as follows ${ }^{10)}$ :

$$
\rho=\frac{6 \pi \varepsilon^{2}}{b^{2}}
$$

where $b$ stands for the Burgers vector of dislocations in ferrite.

Specimens for transmission electron microscopy were machined from $3 \mathrm{~mm}$ diameter rods which were sliced into $100 \mu \mathrm{m}$ discs. These were ground down to $50 \mu \mathrm{m}$ thickness using 1200 grit silicon carbide paper, for electropolishing at $50 \mathrm{~V}$ using a twin jet unit. The electrolyte consisted of $5 \%$ perchloric acid, $15 \%$ glycerol and $80 \%$ methanol. A JEOL JEM-200CX transmission electron microscope operated at $200 \mathrm{kV}$ was used to examine the thin foils. From where it was determine the ferrite true plate thicknesses $t,{ }^{11)}$ by measuring the mean lineal intercept $\bar{L}=\pi t / 2$ in a direction normal to the plate length.

Tensile specimens with a section of $5 \mathrm{~mm}$ diameter and a gauge length of $25 \mathrm{~mm}$ were tested at room temperature using an Instron- 8032 fitted with a $100 \mathrm{kN}$ load cell. A crosshead speed of $0.1 \mathrm{~mm} / \mathrm{min}$ was used in all the experiments. Plane strain fracture toughness $\left(\mathrm{K}_{\mathrm{IC}}\right)$ was obtained on compact tension specimens of $B=13 \mathrm{~mm}, W=26 \mathrm{~mm}$ and $a / W=0.5 \mathrm{~mm}$ tested at room temperature in a servo-hydraulic machine. Where $B$ and $W$ stands for the test piece thickness and width respectively, and $a$ for the effective crack length. The development of the fatigue crack and its propagation by applying an increasing force were done under the requirements of the British standard method $\left(\mathrm{B}_{\mathrm{S}}\right.$ 5447). All mechanical experiments were assisted by electronic equipment that allowed the continuous tracking of load-displacement data during tests. All samples were machined from the softened (pearlitic) bulk material after homogenization and subsequently heat treated to the desired conditions. Load and elongations measured during uniaxial tensile were converted to engineering stress-strain curves.

\section{Results and Discussion}

\subsection{Microstructural Characterization}

$\mathrm{X}$-ray and metallography analysis showed that the general microstructure consisted of a mixture of two phases, plates of bainitic-ferrite and carbon enriched retained austenite, as described in previous works ${ }^{3,4)}$ and illustrated in Fig. 1. This figure summarizes experimental data concerning the microstructure as a function of transformation temperature; the transformation time was in all cases sufficient to ensure the cessation of the bainite reaction.

Due to the low transformation temperatures and the intrinsic characteristics of bainite transformation, paraequilibrium nucleation and diffusionless growth, there are three very distinctive features in the microstructures obtained; first is the small thickness of the ferrite plates that become coarser as transformation temperature increases, about 30 and $65 \mathrm{~nm}$ for alloy 1 and 45 and $54 \mathrm{~nm}$ for alloy 2 in the microstructures obtained at 200 and $300^{\circ} \mathrm{C}$ respectively. This is a consequence of the increased strength of the par-

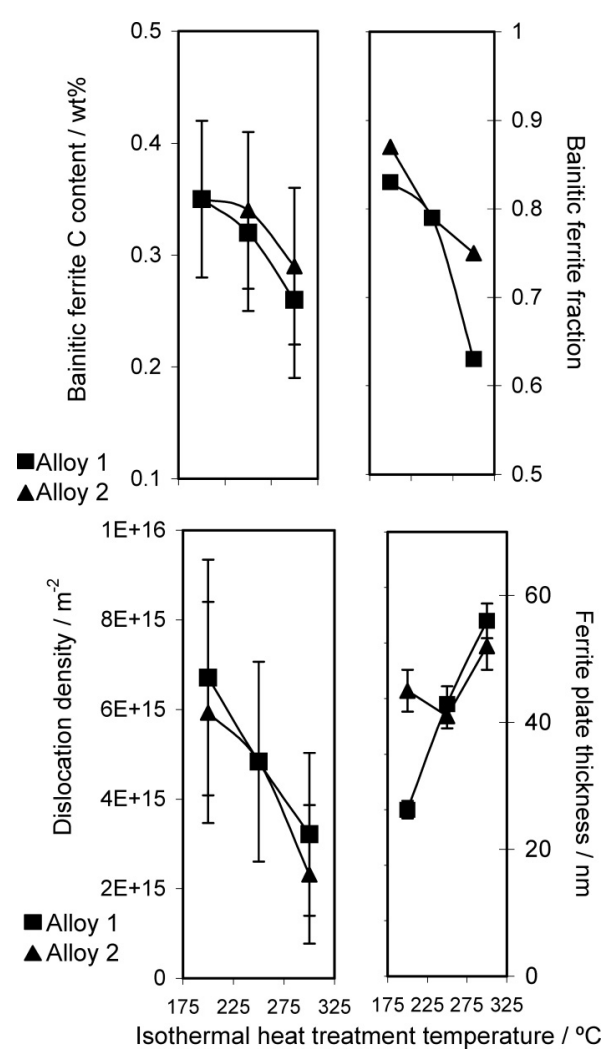

Fig. 1. Summary of quantitative experimental data. Fraction of bainitic ferrite (the remainder being retained austenite), its $\mathrm{C}$ content and dislocation density obtained after isothermal transformation at different temperatures and times, ensuring that bainitic transformation was finished. The thickness refers to $t$, the stereologicaly corrected value. $^{11)}$

ent austenite at low temperatures and the magnitude of the free energy change accompanying transformation. ${ }^{12)}$ The second feature is the high dislocation density measured in ferrite, that increases as the transformation temperature is reduced, ${ }^{1,13)}$ and finally the large amount of carbon, up to $0.35 \mathrm{wt} \%$, which remains trapped inside the bainitic ferrite. This is a consequence of the low transformation temperatures and the displacive nature of bainite reaction, as it will be suggested further on, carbon may be trapped at dislocations in the bainitic ferrite.

\subsection{Mechanical Properties}

Figure 2 presents the transformation temperature dependence of engineering stress versus strain curves. Deformation of bainitic microstructures at room temperature is characterized by continuous yielding, ${ }^{1)}$ as might be expected from microstructures with unlocked dislocations introduced by the plastic accommodation of the shape change. Although there is evidence that ferrite retains an excess concentration of carbon, even after annealing, the majority of dislocations are believed to be mobile. The gradual yielding behavior sometimes persists after stressrelief heat-treatments. There is a variety of obstacles to dislocation motion, (solute atoms, boundaries, thin films of retained austenite), each with a different ability to obstruct plastic deformation. Many of the obstacles are not uniformly distributed so there will exist obstacle-free areas into which dislocations can penetrate at low stresses, thus giving 


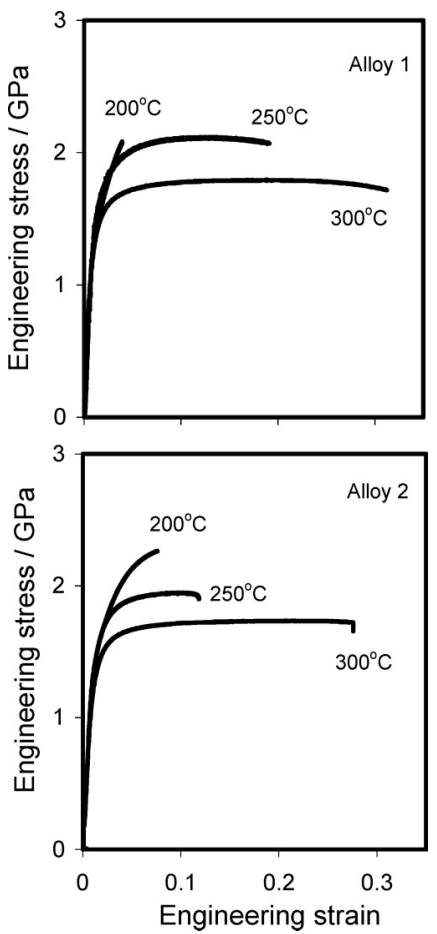

Fig. 2. Engineering stress-strain curves at room temperature, of microstructures obtained following transformation at the temperatures indicated.

rise to a gradual deviation from elastic deformation. Another scale of heterogeneity can arise when a representative fraction of softer phase is included in the microstructure such as blocks of retained austenite. Plastic deformation at first focuses in the softer phase, the hard phase only begins to deform when the softer phase has strain hardened sufficiently to transfer load. Therefore leading to a continuous yielding.

As it is evident in Fig. 2, plastic deformation is uniformly distributed along the gauge length of the samples, showing little or no necking, in other words, most or all of the total elongation achieved is uniform elongation.

Figure 3 contains a summary of the mechanical properties obtained for both steels. The obtained microstructures exhibit an extraordinary combination of properties, with yield strengths (YS) greater than $1.2 \mathrm{GPa}$, and ultimate tensile strengths (UTS) ranging from 1.77 to $2.2 \mathrm{GPa}$, the latter in the case of the $200^{\circ} \mathrm{C}$ microstructure. Such a combination of properties has never before been achieved in bainitic steels. Fracture toughness $\left(\mathrm{K}_{\mathrm{IC}}\right)$ and ductility both decrease as the strength increases. The microstructures obtained by transformation at $300^{\circ} \mathrm{C}$ exhibit total elongation $\sim 30 \%$ and fracture toughness of $44 \mathrm{MPam}^{0.5}$ and $51 \mathrm{MPa} \mathrm{m}^{0.5}$ for alloy 1 and 2 respectively, very high values if compared with those obtained by transformation at $200^{\circ} \mathrm{C}$, where elongation is reduced $\sim 20 \%$ and toughness by almost half.

There are several operative strengthening mechanisms which are expected to contribute to the microstructure strength; size of the bainitic ferrite plates, ferrite dislocation density and the excess carbon concentration in ferrite, Fig. 1. The excess carbon is a consequence of the displacive mode of transformation and its presence has been independently verified using X-ray analysis and atom-probe measurements. ${ }^{14,15)}$ It has been found that there is a strong cor-
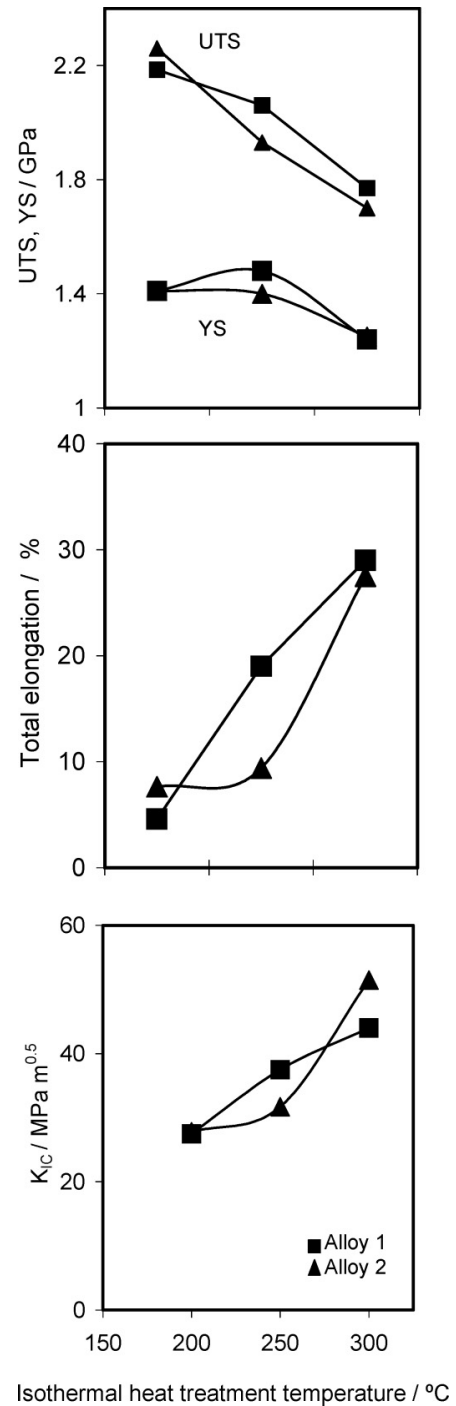

Fig. 3. Transformation temperature dependences of UTS, YS, total elongation and fracture toughness $\mathrm{K}_{\mathrm{IC}}$.

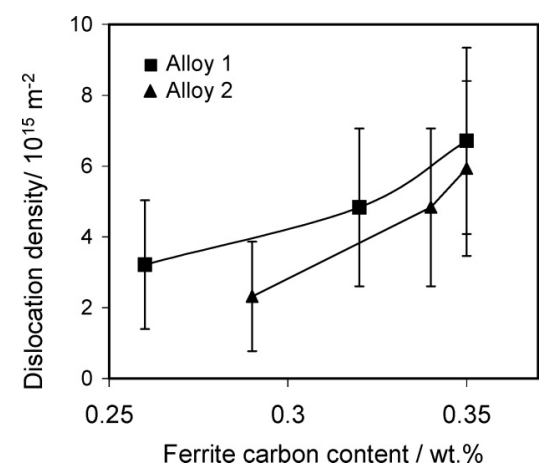

Fig. 4. Plot showing the relation between ferrite dislocation density and its carbon content following transformation

relation between the carbon content and the calculated dislocation density, ${ }^{14)}$ Fig. 4, which suggests that carbon may be trapped at dislocations in the bainitic ferrite, as originally suggested for martensite by Kalish and Cohen. ${ }^{16)}$ Therefore, there may be no independent contribution of carbon in solid solution, but rather, through its effect on the mobility of dislocations.

Theory indicates that the contribution to strength due to the size of the plates is given by $\Delta \sigma \cong 115(\bar{L})^{-117-19)}$ 


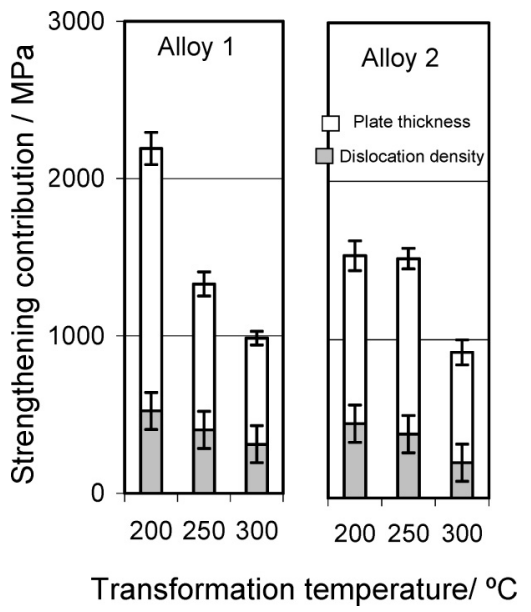

Fig. 5. Strengthening contributions versus transformation temperature after correcting by their corresponding bainitic ferrite fractions.

where $\bar{L} \cong 2 t$ is the mean linear intercept in micrometers, and that due to the dislocation density is given by $\Delta \sigma \cong 7.3410^{-6}(\rho)^{0.5}$ where $\rho^{20)}$ is in $\mathrm{m}^{-2}$, being $\Delta \sigma$ in $\mathrm{MPa}$. In Fig. 5 is represented the contributions of the two strengthening mechanisms in both alloys after correcting by the corresponding bainitic ferrite fractions. It is easily shown that much of the strength of low-temperature bainite is due to the extremely fine plates of ferrite. Thus at the lowest transformation temperatures $\left(200^{\circ} \mathrm{C}\right)$, with $>80 \%$ of the finest bainitic ferrite present in the microstructures the contribution is about 1.6 and $1.1 \mathrm{GPa}$ for alloy 1 and 2 respectively, on the other hand increment due to dislocations is about $500 \mathrm{MPa}$ for both alloys. As transformation temperature increases and the microstructures become coarser and less dislocated, these contributions become weaker i.e. in the microstructures obtained after transformation at $300^{\circ} \mathrm{C},<700 \mathrm{MPa}$ for the plate thickness and 200-300 MPa for the dislocation density were determined.

It is difficult to separate the effect of retained austenite on strength in these steel from other factors. Qualitatively, austenite can affect the strength by transforming to martensite during testing, TRIP effect. The low yield/ultimate tensile strength ratios (YS/UTS) in Fig. 3 are due to the presence of austenite and the large dislocation density in the microstructure. ${ }^{21)}$ Consequently, retained austenite increases the strain hardening rate of the steel. Similarly, toughness and ductility are controlled by the volume fraction of retained austenite, ${ }^{22)}$ ductile phase compared to the bainitic ferrite, and its ability to transform to martensite under strain. This effect strongly depends on the chemical composition and morphology of the retained austenite. ${ }^{23,24)}$ Thus the microstructures obtained after isothermal heat treatment at $300^{\circ} \mathrm{C}$, with austenite fractions of 0.25 and 0.37 for alloy 1 and 2 respectively, exhibit the best results in terms of total elongation and fracture toughness when compared with the stronger microstructures obtained after transformation at lower temperatures, therefore with lower retained austenite presence.

Finally, Fig. 6 compares the properties of the present alloys against published data, ${ }^{25,26}$ highlighting the fact that novel bainitic steels exhibit an exceptional combination of mechanical properties that places this new type of mi-
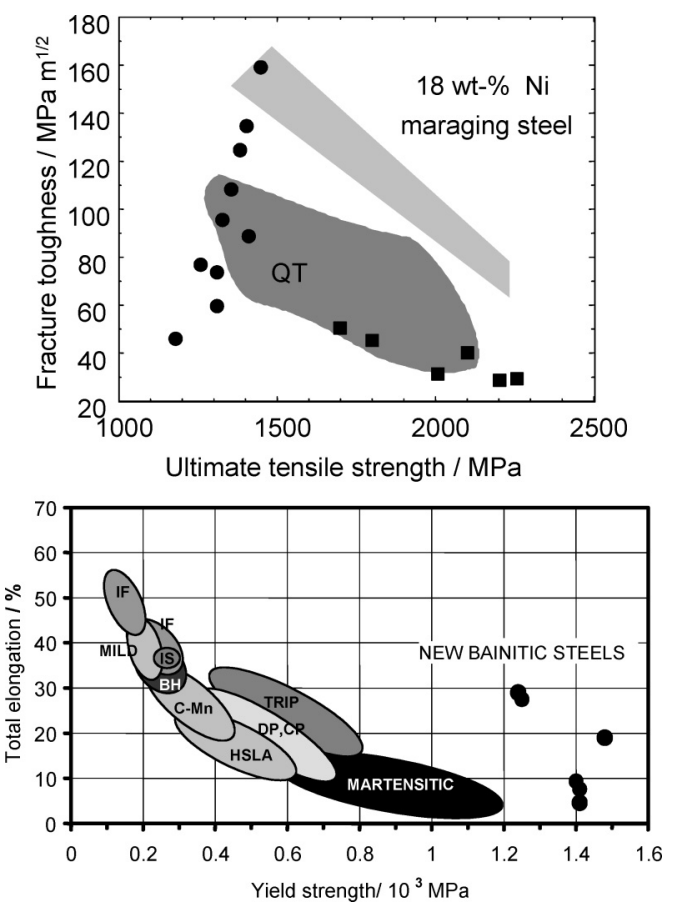

Fig. 6. Comparison of ultimate strength versus fracture toughness of: conventional quenched and tempered steels (QT), maraging steels, bainitic steels ${ }^{25}$ ) (solid circles) and new bainitic steels (solid squares); and strength versus total elongation of conventional steels ${ }^{26)}$ and new bainitic steels. IF, interstitial free; $\mathrm{CMn}$, carbon manganese; $\mathrm{BH}$, bake hardenable; IS, isotropic; DP-dual phase; CP, complex phase.

crostructures in an advantageous position for different applications.

\section{Conclusions}

Novel bainitic microstructures obtained by isothermal transformation at low temperatures $\left(200-300^{\circ} \mathrm{C}\right)$ were tested in order to characterize their mechanical properties. An attempt to correlate the properties with very distinctive microstructural features of this microstructures lead to the conclusion that the extraordinary slender plates of bainitic ferrite in conjunction with high dislocation density in ferrite, are the main strengthening mechanism operating. While, as expected, ductility and fracture toughness are controlled by the amount of softer phase, retained austenite, present in the microstructures. Both, for the extraordinary combination of mechanical properties, never achieved before in bainitic steels, and the simplicity of heat treatment used to develop these microstructures, novel bainitic steels are in an advantageous position for an increasing number of applications ranging from rails to formula one gear boxes.

\section{Acknowledgements}

The authors acknowledge financial support from the Spanish Ministerio de Educación y Ciencia for the financial support in the form of Ramón y Cajal contracts (RyC 2002 and 2004 respectively). Some of this work was carried out under the auspices of an EPSRC/MOD sponsored project on bainitic steels at the University of Cambridge; we are extremely grateful for this support over a period of three years. The authors are extremely grateful to Prof. H. K. D. 
H. Bhadeshia for fruitful discussions.

\section{REFERENCES}

1) H. K. D. H. Bhadeshia: Bainite in Steels, 2nd ed., Institute of Materials, London, (2001).

2) F. G. Caballero, H. K. D. H. Bhadeshia, K. J. A. Mawella, D. G. Jones and P. Brown: Mater. Sci. Technol., 18 (2002), 279.

3) C. Garcia-Mateo, F. G. Caballero and H. K. D. H. Bhadeshia: J. Phys. IV, 112 (2003), 285.

4) C. Garcia-Mateo, F. G. Caballero and H. K. D. H. Bhadeshia: ISIJ Int., 43 (2003), 1238.

5) C. Garcia-Mateo, F. G. Caballero and H. K. D. H. Bhadeshia: ISIJ Int., 43 (2003), 1821.

6) S. H. Song, R. G. Faulkner and P. E. J. Flewitt: Mater. Sci. Eng. A, 281A (2000), 23.

7) M. J. Dickson: J. Appl. Crystallogr., 2 (1969), 176

8) H. K. D. H. Bhadeshia, S. A. David, J. M. Vitek and R. W. Reed: Mater. Sci. Technol., 7 (1991), 686.

9) G. K. Williamson and W. H. Hall: Acta Metall., 1 (1953), 22.

10) G. K. Williamson and R. E. Smallman: Philos. Mag., 1 (1956), 34.

11) E. E. Underwood: Quantitative Microscopy, ed. by R. T. Dehoff and F. N. Rhines, McGraw-Hill, New York, (1968), 78

12) S. B. Singh and H. K. D. H. Bhadeshia: Mater Sci. Eng. A., 245A (1998), 72
13) M. K. Fondekar, A. M. Rao and A. K. Mallik: Metall. Trans., 1 (1970), 885.

14) C. Garcia-Mateo, M. Peet, F. G. Caballero and H. K. D. H. Bhadeshia: Mater. Sci. Technol., 20 (2004), 814.

15) M. Peet, S. S. Babu, M. K. Miller and H. K. D. H. Bhadeshia: Scr. Mater, 50 (2004), 1277.

16) D. Kalish and M. Cohen: Mater. Sci. Eng. A., 6A (1970), 156.

17) H. K. D. H. Bhadeshia: Mathematical Modelling of Weld Phenomena III, Institute of Materials, London, (1997), 229.

18) G. Langford and M. Cohen: Trans. Am. Soc. Met., 62 (1969), 623.

19) G. Langford and M. Cohen: Metall. Trans., 1 (1970), 1478.

20) R. W. K. Honeycombe and H. K. D. H. Bhadeshia: Steels. Microstructure and Properties. Edward Arnold, London, (1995), 311.

21) A. P. Coldren, R. L. Cryderman and M. Semchysen: Steel Strengthening Mechanisms, Climax Molybdenum, Ann Arbor, MI, (1969), 17.

22) B. P. J. Sandvik and H. P. Nevalainen: Met. Technol., 15 (1981), 213.

23) N. K. Ballinger and T. Gladman: Met. Sci., 3 (1981), 95.

24) H. K. D. H Bhadeshia and D. V. Edmonds: Metall. Trans. A, 10A (1979), 895.

25) V. T. T. Miihkinen and D. V. Edmonds: Mater. Sci. Technol., 3 (1987), 441.

26) http://www.worldautosteel.org/ulsab-avc/imagelib/pages/087.htm, (accessed January 2005) 